\title{
The density of collagen fiber in alveolus mandibular bone of rabbit after augmentation with powder demineralized bone matrix post incisivus extraction
}

\author{
Regina TC. Tandelilin*, Abdul Salam M Sofro**, Al Supartinah Santoso*, Marsetyawan HNE Soesatyo***, and Widya Asmara**** \\ * Faculty of Dentistry, Gadjah Mada University, Yogyakarta \\ ** Faculty of Medicine, YARSI University, Jakarta \\ **** Faculty of Medicine, Gadjah Mada University, Yogyakarta \\ **** Faculty of Veterinary Medicine, Gadjah Mada University, Yogyakarta
}

\begin{abstract}
The bone defect due to tooth extraction contributes the most cases reported in the aspects of oral surgery. The defect can be preventively managed by adding powder bone matrix intended for augmentation which eventually induces the formation of new bones. This hard tissue wound healing is preceded by the presence of collagen fibers. The aim of this study was to determine the density of collagen fiber in the alveolus mandibular bone of rabbit which was augmented using powder demineralized bone matrix (DBM) post incisivus extraction. Twenty four male rabbits aged 2.5-3 months weighed 900-1,100 grams were randomly divided into two groups. The treated rabbits were augmented with DBM after the incisivus extraction on mandible. The mucosa was then sutured. On the other hand, the controlled rabbits received similar treatments with those of the treated rabbits except there was no augmentation of DBM. Decapitation of treated and controlled rabbits was made on day 5, 7, 10, and 14 days post surgery, each with three rabbits. Mandibles were cut, decalcified, and imbedded in paraffin block. The staining was done using Mallory. Significant differences in the density of collagen were noted on day 10 and 14 post surgery, indicating that powder demineralized bone matrix successfully induced the stimulation of collagen.
\end{abstract}

Key words: demineralized bone matrix, augmentation, collagen

Correspondence: Regina TC. Tandelilin, c/o: Fakultas Kedokteran Gigi Universitas Gadjah Mada. Jln. Denta No. II, Sekip Utara Yogyakarta 55281.

\section{INTRODUCTION}

The advancement of science in developing tissue transplantation has triggered an increase in the need for tissue replacement, so-called graft. The graft is required for either reconstruction or preventing further tissue deterioration on damaged body tissues. It has been reported that the abnormality of bone in the aspect of oral surgery is bone defect, in most cases engendered by tooth extraction. ${ }^{1}$ Bone grafting is often essential in providing the best possible set of conditions for the anchorage of implants or augmentation in areas lacking in quality or quantity of bone to induce bone formation. ${ }^{2}$ There are heaps of different materials available for the augmentation of the alveolar bone. Freeze dried powder demineralized bone graft or demineralized bone matrix (DBM) is a bone that has been treated with acid, then washed and followed by sterilization using $\gamma$ (gamma) radiation to help extend shelf life.

The utilisation of that type of allograft was reported effective with less risk of complication. ${ }^{3}$ Previous studies show that DBM is able to induce ectopic bone formation in subcutaneous and intramuscular pockets in rodents. ${ }^{4,5}$ This bone induction process has been studied extensively. 6,7 Histological and biochemical analyses show that cartilage appears 5-10 days after implantation of active DBM. ${ }^{8}$ Study of Wang ${ }^{6}$ reports that this cartilage is mineralized by day 7-14 and subsequently replaced by bone. As DBM-related bone formation can be observed afterwards to occur at ectopic sites, it is assumed that pluripotent mesenchymal are attracted to the site of implantation. The use of allograft powder DBM leads bone tissue to be fully incorporated into patient's tissue by a well established biological mechanism, and in treating bone defects has been proven beneficial for bone regeneration of both animals and humans.9,10 Demineralized bone matrix (DBM) powder form comprises collagenous and non-collagenous. Urist determined that the osteoinductive fraction could be extracted from the organic component of bone, which he termed bone morphogenic protein (BMP). The BMPs are embedded in bone matrix. ${ }^{11}$ In addition to BMPs, other growth factor such as platelet derived growth factor (PDGF) and transforming growth factor (TGF- $\beta$ ) were found. ${ }^{12}$

Wound healing is basically a complex process in which a variety of cellular and matrix components act in concert to re-establish the integrity of injured tissues. The complexity of this process may be simplified into temporal sequence of normal healing: haemostasis, inflammation, cell proliferation (repair), and tissue remodelling. During 

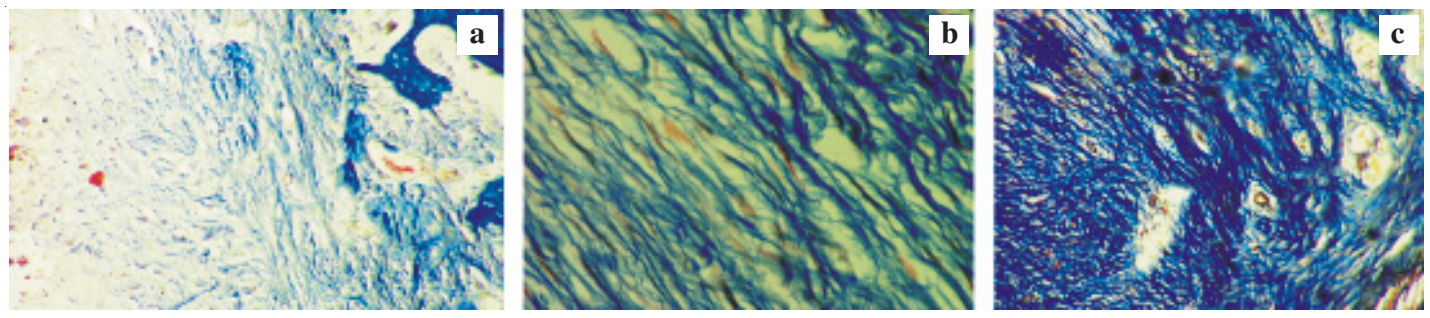

Figure 1. (a) Score of the collagen fiber density showing the range of low collagen density, (b) Medium collagen density, and (c) High collagen density.

the evolution process, a group of structural protein develops, variously modified in terms of rigidity, elasticity, and strength levels, depending on the environmental influence and functional needs known as collagen. For instance, collagen on skin, bone, cartilage, and basal membrane. Collagen is protein mostly found in humans and reaches $30 \%$ of the dry weight. The collagen consists of glysine amino acid $(33.5 \%)$, prolin $(12 \%)$, hidroxy prolin $(10 \%)$, and the remaining substances such as other amino acids. Type I collagen is the most spread one, found in the tissue as a classical structure renowned as collagen fiber. These fibers support bones, dentin, tendon dermis, etc. Type II collagen is mostly found in hyaline and elastic cartilage, whose shape is fibrous and very smooth. ${ }^{13}$ On day 7 in the process of wound healing on bone, the synthesis of type II collagen appears whilst type I collagen generally prevails on day $10-12 .{ }^{7}$ When observed by light microscope, the collagen fiber is acidophilic, appears to be pink by Van Geyson and blue by Mallory trycom. Collagen fibers comprise thick fibers solidly suppress each other with diameters approximately $75 \mathrm{~nm}$ in mammals. In many parts of body, collagen fibers are conceived in parallel series forming collagen bundles. ${ }^{13}$ The objective of this study was to determine the density of collagen fibers on alveolus mandibular bone of rabbit which was augmented using powder DBM post-incisivus extraction.

\section{MATERIALS AND METHODS}

This study was done pure experimentally using posttest only group control design. Twenty-four male rabbits aged 2.5-3 months with weights of 900-1,100 grams were randomly divided into two groups. The first treated group I was augmented by powder DBM (370-710 $\mu \mathrm{m})$ post-incisivus extraction, whilst the other group was not augmented, hence used as a controlled group. Demineralized bone matrix (DBM) in the form of allograft made from cortical bone of rabbit was prepared by the Bank of Tissue Dr Soetomo RSUD Dr. Soetomo, Surabaya. The rabbits were injected with intra muscular with penobarbital sodium $100 \mathrm{mg} / \mathrm{kg}$ body weight; then after they were calm and sleepy, they were injected with $0,2 \mathrm{ml} / \mathrm{kg}$ body weight of $2 \%$ Lidocaine $\mathrm{HCl}$ (Phapros, Semarang) on incivus tooth labial. After the extraction ended, the wounds were cleaned by sterilized cotton, and gingival were pressed to control bleeding problem. Subsequently, they were immediately augmented by DBM that has been mixed with the solution of lactate ringer. DBM was pressed to get in and fill the tooth sockets on mandible. Mucosa crease was then sutured by non-absorbable suture No. 5 (Ethycon silk suture). Analgesic (250 mg) was also included into the liquid of ad libitum $250 \mathrm{ml}$ only for two days after surgery. The food given was pellet (Japfa Comfeed, Indonesia) and aquadest.

On days 5, 7, 10 and 14 post-surgery, three rabbits from each group randomly took to be decapitated. Mandible as wide as incisivus tooth was cut and submerged into the solution of Lylis as the fixative solution and decalcification for 3-5 days. Then the process was followed by $70 \%$ of alcohol as bone submersion solution for three days. Subsequently, the bone was vertically cut in line with tooth axis using microtome and was imbedded in paraffin block. Furthermore, the tissue was again cut as wide as $6 \mathrm{~mm}$ and put on object glass and processed for Mallory staining. The observation on collagen fiber density was conducted on ten view fields under light microscope with the 4x 100 objective. Criteria for valuation are: Score 1 shows that the density of collagen fiber is low (Figure 1-a); score 2 depicts that collagen fiber is medium (Figure 1-b); and score 3 shows very high density (Figure 1-c). In order to analyse the density data of the collagen fibers, Mann-Whitney Test was utilized.

\section{RESULTS}

Table 1 below shows the mean and standard deviation of the collagen fiber density of mandibular bone for each group. The pattern of collagen fiber density was summarized in Figure 2.

General description shown in Figure 2 indicates that on day 7, collagen fiber density of DBM group was higher (denser) than that control group (without augmentation). Meanwhile, histological description depicts that the formation of collagen fiber in DBM-augmented group is getting higher on day 7 after being wounded although histologically there has yet to show the prevalence of collagen bundle. This phenomenon is of difference from 
Table 1. Mean and standard deviation of the density of mandibular fiber collagen on control and DBM groups

\begin{tabular}{cccc}
\hline $\begin{array}{c}\text { Time after } \\
\text { augmentation }\end{array}$ & $\mathrm{N}$ & $\begin{array}{c}\text { Control } \\
\overline{\mathrm{X}} \pm \mathrm{SD}\end{array}$ & $\overline{\mathrm{X}} \pm \mathrm{SD}$ \\
\hline Day 05 & 30 & $1.53 \pm 0.73$ & $1.56 \pm 0.62$ \\
Day 07 & 30 & $1.80 \pm 0.76$ & $2.11 \pm 0.79$ \\
Day 10 & 30 & $1.90 \pm 0.84$ & $2.43 \pm 0.67$ \\
Day 14 & 30 & $1.93 \pm 0.63$ & $2.50 \pm 0.57$ \\
\hline
\end{tabular}

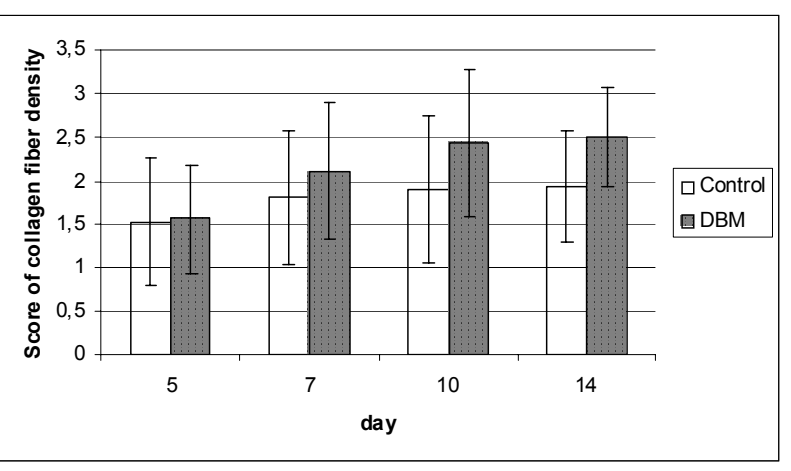

Figure 2. The increase in density of collagen fiber on the mandibular bone post surgery based on observation day of control and DBM groups.

that on day 5, showing that collagen fibers of the two groups are relatively few with similar mean values and without twist of collagen fiber. On day 10 after being wounded, DBM group shows the existence of collagen fiber bundle which appears to be denser after 14 days of treatment. On the other hand, the controlled group has also shown collagen bundle but the distance is not as dense as that of DBM group. Subsequently, the mean rank of collagen fiber density in each group predicated upon treatment days is described in Table 2.

The difference significance of collagen fiber density of mandibular bone is graphed in Table 3 . As seen, there was no significant difference of collagen fiber density on day 5 and 7 after the extraction wounds. The difference was significant on day 10 and 14 in the wake of DBM

Table 2. Mean rank and sum of ranks of the density of the mandibular collagen fiber on control and DBM groups

\begin{tabular}{lcccc}
\hline Group & $\begin{array}{c}\text { Time after } \\
\text { augmentation }\end{array}$ & N & $\begin{array}{c}\text { Mean } \\
\text { Rank }\end{array}$ & $\begin{array}{c}\text { Sum of } \\
\text { Ranks }\end{array}$ \\
\hline Control & Day 5 & 30 & 29.60 & 888.00 \\
DBM & & 30 & 31.40 & 942.00 \\
Control & Day 7 & 30 & 26.70 & 801.00 \\
DBM & & 30 & 34.30 & 102.90 \\
Control & Day 10 & 30 & 25.25 & 757.50 \\
DBM & & 30 & 35.75 & 1072.50 \\
Control & Day 14 & 30 & 23.78 & 713.50 \\
DBM & & 30 & 37.22 & 1116.50 \\
\hline
\end{tabular}

Note: $\mathrm{DBM}=$ powder demineralized bone matrix.
Table 3. Mann-Whitney test of the density of the mandibular collagen fiber on control and DBM groups

\begin{tabular}{cc}
\hline Time after Augmentation & Assym. Sig (2 -tailed) \\
\hline Day 05 & 0.653 \\
Day 07 & 0.73 \\
Day 10 & $0.013^{* *}$ \\
Day 14 & $0.010^{* *}$ \\
\hline
\end{tabular}

augmentation. The results indicate that powder demineralized bone matrix induces the collagen fiber stimulation after the augmentation on rabbit alveolus mandibular post- incisivus extraction.

\section{DISCUSSION}

Results of this study tend to indicate that DBM powder of allograft can induce bone collagen fiber stimulation on mandible in post-extraction period. This fact substantiates previous studies that also show the capability of DBM of inducing collagen stimulation. ${ }^{7,14}$ Since the initial studies conducted by Urist ${ }^{4}$ the osteoinductive capacity of DBM has been well established. ${ }^{15} \mathrm{DBM}$ is produced by the extraction of human cortical bone and the components of the bone that remain behind including the non-collagenous proteins; bone osteoinductive growth factors, the most significant of which is BMP, and the type I collagen. ${ }^{14}$ DBM in this study is allograft in the form of freeze dried powder which could be stored at room temperature and is sterilized using $\gamma$ (gamma) ray. These processes yield a dry granular material that consists of collagen matrix in which BMPs and other insoluble growth factors are embedded. This condition is also in line with the use reported as effective grafting materials. ${ }^{3}$

The major phases of the osteoinduction are chemotaxis, mitosis, and differentiation. ${ }^{16}$ Chemotaxis may be defined as the directed migration of cells in response to a chemical gradient. Implantation of allograft DBM powder promotes chemotaxis of cells to vicinity. Plasma fibronectin binds avidly to the implanted bone matrix. ${ }^{17,18}$ Fibronectin is a protein that has affinity for collagen, fibrin, and heparin, the major components in the site of any skeletal trauma. It is well known that peptides of fibronectin are chemotactic and perhaps mitogenic. ${ }^{7}$

The major constituents of the demineralized bone matrix (powder) are collagen and other matrix proteins. The mineralization process that occurs in hard tissues of the body relies upon this extracellular matrix. It has generally been agreed that fibrillar collagen, the primary component of this matrix, has the capacity to serve as the structural framework in tissue that is undergo mineralization. ${ }^{19}$

One of the bone healing parameters is the growing collagen fibers. This study's results indicate a significant difference of collagen fiber density on day 10 and 14 after the tooth extraction. It is apparent that collagen fiber 
density, supposed to be type I and II on DBM-augmented alveolus, is denser. Collagen fibers on mandibular alveolus are mostly type I and II. This condition is in line with the study of Reddi et al. ${ }^{7}$ reporting that the synthesis of type I collagen prevails between day 10 and 12 in the process of bone induction of DBM implantation. Bone matrix consists mainly of collagen fibers (approximately 90\%) and noncollagenous proteins. Type I collagen, which plays structural as well as morphogenic roles and provides scaffolding for mineral crystals, is the major species roles and within lamellar bone, the fibers are forming arches for optimal bone strength. ${ }^{20}$ Accordingly, allograft powder of DBM as the augmentation materials is capable of hastening bone reconstruction by inducing biosynthesis of collagen fibers stimulation for bone strength.

The effect of bone healing augmented by powder allograft of DBM is possibly caused by several growth factors that it contains, such as BMP, PDGF, GDF and TGF$\beta 1$, that synergically cooperating with local recipient cells that influence the proliferation of cells involved in bone healing. The main action of BMPs is to commit undifferentiated pluripotential cells to differentiate into cartilage and bone-forming cells. ${ }^{21,22}$ BMPs are basically abundant in bone and belong to the transforming growth factor- $\beta$ (TGF- $\beta$ ) superfamily, which consists of a group of related peptide growth factors. ${ }^{23}$ The mechanisms of polypeptide growth and differentiation factors (GDFs) on the repair and regeneration of tissues have been shown to have pleitropic effects on wound repair in nearly all tissues. ${ }^{22,24}$ The expression of various GDFs following bone and soft tissue injury may regulate the repair and or regenerative process.

Previous studies have shown that acidic and basic FGF are found in bone matrix ${ }^{25}$ and in vitro; both forms stimulate DNA synthesis and cell replication. ${ }^{26}$ Of significance, the bFGF potently stimulates angiogenesis that is critical for the vascular invasions of bone. ${ }^{27}$ TGF- $\beta 1$ has itself shown to be a strong promoter of extracellular matrix production in many cell types. The effects of TGF- $\beta 1$ appear to be highly dependent upon bone cell source and local environment. ${ }^{28}$ This growth factor stimulates type I collagen, fibronectin, and osteonectin biosynthesis as well as bone matrix deposition and chemotaxis. ${ }^{29}$ This study's results substantiate that of Contran et al. ${ }^{30}$ finding that the collagen synthesis in the healing process is influenced by some factors such as PDGF, FGF, TGF- $\beta$, and cytokins IL-1 and IL-4 secreted by leukocyte and fibroblast.

The conclusion of the stimulation of collagen synthesis on alveolus of rabbit mandibular bone post-incicivus extraction has proven significantly induced by demineralized bone matrix augmentation. The density of collagen fiber per se is of significant difference on day 10 and 14 after the augmentation of demineralized bone matrix post incisivus extraction.

\section{ACKNOWLEDGEMENTS}

This study was supported by BPPS of Directorate of Higher Education, Department of National Education. We confer sincere appreciation to Dr. Totok Utoro, Ph.D for our invaluable discussion on collagen fiber criteria. Eventually, we sincerely thank to Dr. Didik Setyo H., Dr. Rini Maya Puspita, and Andreas AK. Tandelilin, for their helps as blind reviewers on collagen scoring in this study.

\section{REFERENCES}

1. Mercier P. Resorption patterns of the residual ridge. In: Block MS, Kent JN, editors. Endosseus implants for maxillofacial reconstruction. Philadelphia, London, Toronto, Montreal, Sidney, Tokyo: WB Saunders Co; 1997. p. 10-16.

2. Marx RE. Mandibular reconstruction. J Oral Maxillofac Surg 1993; $151: 466$.

3. Wilkins RM, Stringer EA. Demineralized cortical bone powder: Use in grafting space occupaying lesions of bone. Int Orthop 1994; 2: 71-8.

4. Urist MR. Bone: Formation by autoinduction. Science 1965; 150:893-9.

5. Van de Putte KA, Urist MR. Osteogenesis in the anterior of intramuscular implants of decalcified bone matrix. Clinical Orthopaedic and Related Research 1965; 257-70.

6. Wang EA. Bone morphogenetic proteins (BMPs): Therapeutic potential in healing bony defects. Trends in Biotechnology 1993; 11:379-83.

7. Reddi AH, Wientroub, Muthukumaran N. Biologic principles of bone induction. Orthopaedic of North America 1987; 18:207-12.

8. Sampath TK, Reddi AH, Homology of bone-induction proteins from human, monkey, bovine and rat extracellular matrix. Proceeding of the National Academy of Science of the USA 1983; 80:6591-95.

9. Gepstein R, Weiss RE, Hallel T. Bridging larged defects in bone by demineralization bone matrix in the form of a powder. A radiographic, histological, and radioisotope-uptake study in rat. J Bone and Joint Surgery, American 1987; 69:984-92.

10. Einhorn TA, Lane JM, Burstein AH, Kopman CR, Vigrota VJ. The healing of segmental bone defects. J Bone and Joint Surg, American 1984; 66:274-79.

11. Urist M, Strates B. Bone morphogenetic protein. J Dent Res 1971; 50(Suppl 6):1392.

12. Wozney JM. Overview of bone morphogenetic proteins. Spine 2002; 27(165):S2-S8.

13. Jungueira LC, Carneiro J, Kelley R. Basic histology. $8^{\text {th }}$ ed. Jakarta: EGC Publisher; 1995. p. 91-120.

14. Tuli SM, Singh AD. The osteoinductive property of decalcified bone matrix: An experimental study. J Bone Joint Surg Br 1978; 60: 116-23.

15. Ludwig SC, Kowalski JM, Boden Sd. Osteoinductive bone graft substitutes. J Eur Spine 2000; 9(Supple 1):S119-S125.

16. Reddi AH. Extracellular matrix and development. In: Piez KA, Reddi AH, editors. Extracellular matrix biochemistry. New York: Elsevier; 1984. p. 375-412.

17. Weiss RE, Reddi AH. Synthesis and localization of fibronectin during collagenous matrix-mesenchymal cell interaction and differentation of cartilage and bone in vivo. Proc Nat Acad Sci USA 1980; 77: 2074-78.

18. Weiss RE, Reddi AH. Role of fibronectin in collagenous matrixinduced mesencymal cell proliferation and differentation in vivo. Exp Cell Res 1981; 133:247-54.

19. Miller EJ, Martin GR. The collagen of bone. Clin Orthop1968; 59:195. 
20. Groeneveld HJ, Van den Bergh JPA, Holzman P, Ten Bruggenkate CM, Tuinzing DB, Burger EH. Mineralization processes in demineralization bone grafts in tissue floor elevations. J Biomed Mat and Res 1999; 48:393-402.

21. Zhang M, Powers RM, Wolfinbarger L. Effect(s) of the demineralization process on the osteoinductivity of demineralized bone matrix. J Periodontol 1997; 68:1085-92.

22. Ripamonti U, Reddi AH. Periodontal regeneration. Potential role of bone morphogenetic proteins. J Periodont Res 1994; 29:225-35.

23. Groeneveld EHJ, Burger EH. Bone morphogenic proteins in human bone regeneration. Eur J Endocrin 2000; 142:9-21.

24. Graves DT, Concran DL. Mesencymal cell growth factors. Crit Rev Oral Biol Med 1990; 1:17-36.

25. Globus RK, Plouet J, Gospodarowicz D. Cultured bovine osteoblasts synthesize basic fibroblast growth factor and store it in their extracellular matrix. J Endocrin 1989; 124: 1529-47.
26. Canalis E, Mc Carty T, Centrella M. Effects of basic fibroblast growth factor on bone formation in vitro. J Clin Invest 1988; 81: 1572-77.

27. Folkamn J, Klasburn M. Angiogenic factors. Science 1987; 235: 442-47.

28. Centrella M, Mc Carhty TL, Canalis E. Transforming growth beta is a bifunctional regulator of replication and collagen synthesis in osteoblast-enriched cell cultures from fetal rat bone. J Biol Chem 1987; 262:2869-74.

29. Bonewald LF, Mundy GR. Role of transforming growth factor-beta in bone remodelling. J Clin Orthop 1990; 250:261-76.

30. Contran R, Kumar V, Collins T, Tissue repair: Cellular growth, fibrosis, and wound healing. In: Robbins pathologic basic of disease. $8^{\text {th }}$ ed. Philadelphia: WB Sounders Co; 1999. p. 89-112. 